Bangladesh J. Sci. Res. 26(1\&2): 29-36, 2013 (December)

\title{
LEVEL OF NOISE POLLUTION AT DIFFERENT LOCATIONS IN TANGAIL MUNICIPAL AREA, BANGLADESH
}

\author{
M. M. M. Hoque, L. K. Basak, M. Rokanuzzaman and Sajal Roy* \\ Department of Environmental Science and Resource Management, \\ Mawlana Bhashani Science and Technology University, Santosh, Tangail-1902, Bangladesh
}

\begin{abstract}
The study was carried out to ascertain the level of noise pollution at different locations in Tangail municipal area. For this purpose noise levels were measured at different locations at different periods of the day. At all the locations the level of noise were found to be higher than the acceptable level. The intensity of noise was found lower with increasing distance from the road side. The noise level on the main road near hospital, shopping center and bazars was above the standard level recommended by MoEF. From the survey motor vehicles were found as the main cause of high noise level. The most common problems with high noise level were found to increased heart beat, drowsiness, headache and hearing impairment.
\end{abstract}

Key words: Decibel, noise level, noise pollution, municipal area.

\section{Introduction}

Pollution is the introduction of any substance into an environment that causes instability, disorder, harm or discomfort to the ecosystem. Noise pollution (also termed as sound pollution) refers to undesirable levels of noises caused by human activity especially the urbanization and the development of transport and industry that disrupt the standard of living in the affected area. Noise pollution is not only a problem in the developed countries, but it is also a problem for developing countries like Bangladesh. In Bangladesh noise pollution is one of the talked topics of the day. At present noise level in Dhaka city is estimated to be ranging from 60 to $100 \mathrm{~dB}$. If present situation continues then by the year 2017, 50\% people of Dhaka city will lose $30 \mathrm{~dB}$ of hearing power (Alam 2009). Noise from road vehicles produces disturbance to more people than from any other source of noise and has been increasing very fast over the last few decades. Transportation noise is a key problem in the cities of the world today (Aftab et al. 2007). Other than vehicles, noise pollution can be caused by unnecessary use of construction of buildings, industries, microphones and cassette players. Industrial noise is becoming a big source of noise pollution in our country (Sultana et al. 2011). Noise pollution affects human health and can contribute to a general deterioration of environmental quality. It may cause hypertension, disrupt sleep and/or hinder cognitive development in children. The effects of excessive noise could cause a permanent loss of memory or a psychiatric disorder (Babish et al. 1993). The hearing

\footnotetext{
*Corresponding author: Department of Soil Science, University of Chittagong, Chittagong-4331, Bangladesh.
} $<$ du_sajal@yahoo.com>. 
ability of the inhabitants of the city reduces due to long term exposure to high noise level (Das 2001). In Bangladesh due to noise pollution millions of people are exposed to a number of health risks. Pregnant women, aged persons and children are badly affected by noise pollution. The objectives of this study were to determine the level of noise at different locations of Tangail municipality area, the causes and effects of noise pollution on the population.

\section{Materials and Methods}

Noise levels were measured at six main locations of Tangail municipality including Santosh, Shantikunja More, Nirala More, Old Bus stand, New Bus stand and Bazitpur. These areas cover educational institutions, hospitals, mosques, temples, residential, commercial and industrial areas. The sound levels were measured at different time periods. The survey was done in various important points of Tangail municipality area such as near roads, educational institutions, healthcare centers, auto rickshow stands and bus stands. The people of different ages were surveyed to get the real information about the problems they are facing because of traffic noise. Sampling was done in a random away.

Survey data were collected through in depth interview of respondents. To obtain information, a questionnaire was prepared representing all the aspects of noise. There are different types of questions such as ranking, open-ended, close-ended. Close-ended questions are most in number. Then the open-ended questions were turned into closed-ended questions and grouped.

The intensity of the noise is most conveniently measured in $\mathrm{dB}$ decibel $(\mathrm{dB})$. The $\mathrm{dB}$ scale ranges from 0 , the threshold of hearing to about $140 \mathrm{~dB}$, the threshold of pain. The intensity, I, of a sound can be determined with the precision and is related to the amount of sound energy received per sec. from the source of the sound. The intensity level is ten times the log of the intensity ratio.

$$
\mathrm{IL}=10 \log 10\left(\frac{\mathrm{I}}{\mathrm{Io}}\right)
$$

Since the intensity is directly proportional to the square of the pressure, the sound pressure level (SPL) in $\mathrm{dB}$ can be defined by:

$$
\text { Sound pressure level }(\mathrm{dB})=10 \log 10\left(\frac{\mathrm{P}}{\mathrm{Po}}\right)_{2}=20 \log 10\left(\frac{\mathrm{P}}{\mathrm{Po}}\right)
$$

where, $\mathrm{P}=$ reference pressure in $\mathrm{Nm}^{-2}, \mathrm{P}_{0}=$ Reference pressure usually $2 \times 10^{-5}$

The A-weighted sound level, expressed as $\mathrm{dBA}$, is the generally accepted scale for measurement of general noise level, where A indicates the weightage used, gives more weight to high frequency. The A-weighted sound level is devised to represent a person's subjective response to the variation of sound more accurately.

Noise levels were measured by a sound level meter (Multi-function Environmental Meter, Model:ST-8820, Made in China) which consists of a microphone that converts the pattern of sound pressure fluctuations into a similar pattern of electric voltage, amplifiers and a voltage meter that is normally calibrated to read in decibel. 
The open-ended questions were converted into the group, and in the aspects of noise the collected data were tabulated. Computer program such as SPSS program and Microsoft excel were used to process and analyze the data.

\section{Results and Discussion}

The noise levels at different times of the day at different locations of Tangail municipal area are presented in Table 1. The locations are residential, commercial, and mixed areas of Tangail municipality area. The highest average level of sound (85.6 dBA) was observed at New bus stand and lowest average level of sound $(69.0 \mathrm{dBA})$ was observed at Santosh. At all the locations the highest noise levels were found from 11 a.m. - 3 p.m. (highest of 95.3 and $75.9 \mathrm{dBA}$ at New bus stand and Old bus stand, respectively). In a study, conducted by Aftab et al. (2007) maximum average noise level was recorded during day time because of high traffic flow in peak working hours.

Table 1. Noise levels (dBA) at different locations of Tangail municipal area.

\begin{tabular}{lcccccc}
\hline Time interval & \multicolumn{7}{c}{ Locations } \\
\cline { 2 - 7 } & Santosh & Shantikunja & Nirala & Old Bustand & New Bustand & Bazitpur \\
\cline { 2 - 6 } Land-use type & Res. & Mixed & Comm. & Mixed & Mixed & Res. \\
7 a.m. - 11 a.m. & 69.7 & 77.3 & 78.5 & 80.9 & 81.5 & 72.5 \\
11 a.m. - 3 p.m. & 75.9 & 80.5 & 82.3 & 89.4 & 95.3 & 79.8 \\
3 p.m. - 7 p.m. & 67.5 & 79.8 & 81.9 & 85.3 & 86.4 & 78.6 \\
7 p.m. - 11p.m. & 62.7 & 72.3 & 74.5 & 77.6 & 79.3 & 69.8 \\
Average & 69.0 & 77.5 & 79.3 & 83.3 & 85.6 & 75.2 \\
\hline
\end{tabular}

The variations in noise levels at different periods of a day with the distance from roadside of Tangail municipal area are put in Table 2. It was observed that the average noise level near the road side is about $76 \mathrm{dBA}$ and decreased with increasing distance. The lowest average noise level of $53.2 \mathrm{dBA}$ was found at $75 \mathrm{~m}$ distance from road side. The noise levels near road side exceeded the sound limit of $60 \mathrm{dBA}$ standard for mainly residential area but simultaneously used for commercial and industrial purposes (MoEF 1997). The noise level reduces to about $60 \mathrm{dBA}$ at about $60 \mathrm{~m}$ away from the road side. Similar result was found by Alam et al. (2001) where average noise level was found to be decreased from $78.08 \mathrm{dBA}$ at $0 \mathrm{~m}$ to $49.12 \mathrm{dBA}$ at $90 \mathrm{~m}$.

Noise levels at different times of the day at different hospitals near road were measured. Fig. 1 shows that the noise levels near hospitals ranged from $71.6 \mathrm{dBA}$ (7 a.m. - 11a.m.) to $94 \mathrm{dBA}$ (11 a.m. - 3 p.m.). The highest value was found near Saba Clinic and Hospital and the lowest value near Khanam Memorial Hospital. The highest levels of noise were found during11 a.m. - 3 p.m. The noise level during this period of time was the highest because patients mostly came to the doctor during this period. The perfect sound condition for Bangladesh is $45 \mathrm{dBA}$ for the day-time and $35 \mathrm{dBA}$ for the night in peaceful areas and $50 \mathrm{dBA}$ for the day-time and $40 \mathrm{dBA}$ for the night in residential areas (Alam 2009). All the values were found higher than the perfect levels. 
Table 2. Relationship between noise levels (dBA) and distance (m).

\begin{tabular}{lcccccc}
\hline Time Interval & \multicolumn{7}{c}{ Distance from road side (meter) } \\
\cline { 2 - 7 } & 0 & 15 & 30 & 45 & 60 & 75 \\
\cline { 2 - 6 } 7 a.m.- 11 a.m. & 80.9 & 70.6 & 64.6 & 65.9 & 58.9 & 52.6 \\
11 a.m.- 3 p.m. & 80.8 & 73.7 & 68.0 & 62.1 & 58.1 & 53.3 \\
3 p.m.- 7 p.m. & 73.0 & 67.6 & 66.1 & 63.4 & 60.8 & 52.1 \\
7 p.m. -11 p.m. & 71.4 & 68.6 & 66.5 & 62.9 & 58.9 & 54.9 \\
Average & 76.5 & 70.1 & 66.3 & 63.6 & 59.2 & 53.2 \\
\hline
\end{tabular}

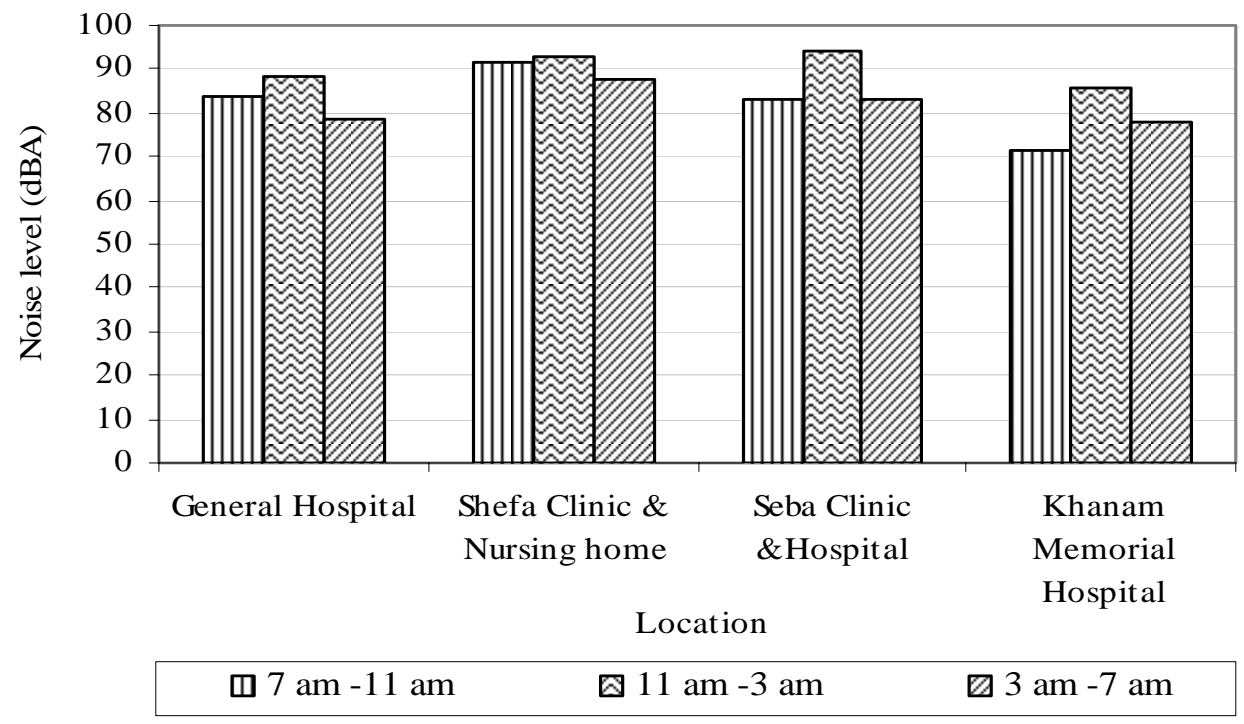

Fig. 1. Variation of noise levels with time at different hospitals.

Noise levels at different times of the day near different shopping centers are shown in Fig. 2. All the values were found to be greater than the standard level. From Fig. 2 the highest level (90 $\mathrm{dBA}$ ) was found in the evening (4 p.m. - 8 p.m.) near Pouro Market. During 8 a.m. - 12 p.m. the highest level was also found (86.5 dBA) near Pouro Market. However, during 12 p.m. - 4 p.m. the maximum value of $85.6 \mathrm{dBA}$ was found near Tangail Super Market. During 8 a.m. - 12 noon the noise level was found to be the lowest (75.7dBA) near Capsule Market, during $12 \mathrm{pm}$ - 4 pm near Somobai Super Market (75.2 dBA) and during 4 p.m. - 8 p.m. near Tangail Plaza (80.9 dBA). These high noise levels near shopping centers are attributed to human gathering, vehicular traffic, particularly auto rickshaw and frequent use of the pressure horns by buses and trucks. The high noise level occurs during day-time as people travel to and from schools, markets and work places (Ahmad and Khan 2003). 


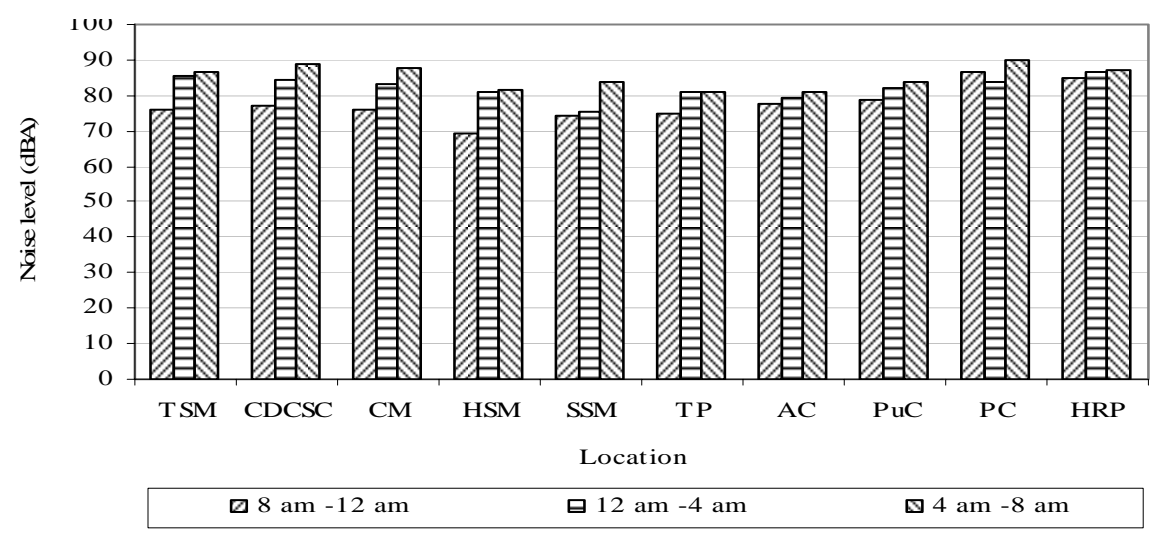

Fig. 2. Variation of noise levels with time at market. *TSM- Tangail Super Market, CDCSC- C.D.C. Snoping Complex, CM- Capsule Market, HSM- Hira Super Market, SSM- Somobai Super Market, TP- Tangail Plaza, AC- Ali Complex, PuC- Purobi Complex, PC- Pouro Complex, HRP- HobiorRahman Plaza.

Fig. 3 shows the noise levels near different Bazars at different times in Tangail municipality area. During the period of 7 a.m. - 11 a.m. the highest noise level was found at Park Bazar which was 84.1dBA and lowest value of $74.5 \mathrm{dBA}$ was observed at Panchani Bazar. The highest level of noise at Park Bazar in morning is due to the human gathering. During the period of 11 a.m. - 3 p.m. and 3 p.m. - 7 p.m. the Baby Stand Kacha Bazar was found to be the highest noise polluted

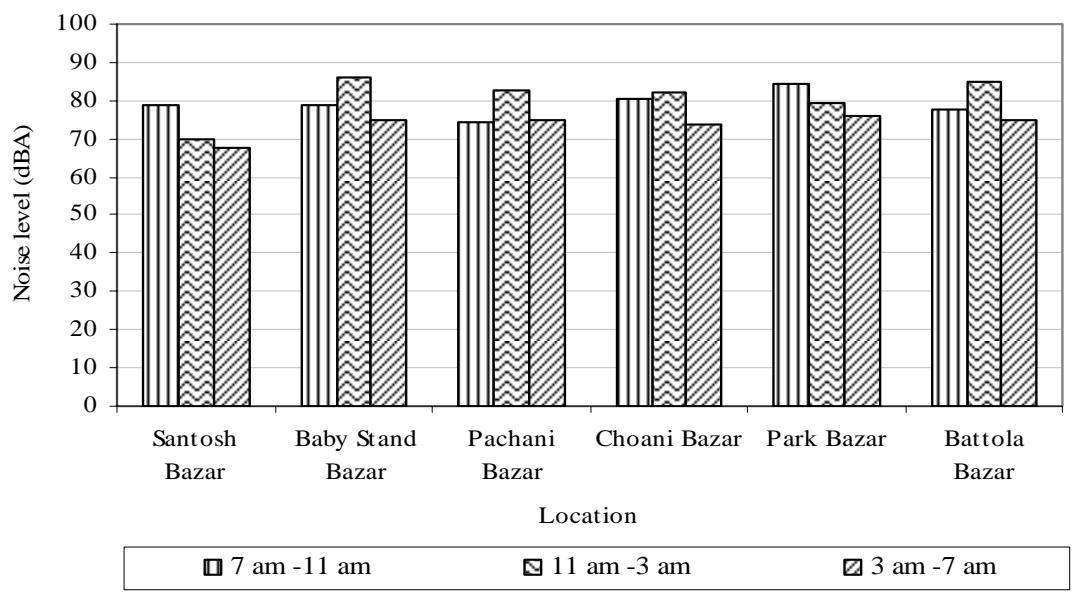

Fig. 3. Variation of noise levels with time at bazaars.

place (85.8 dBA). Santosh Bazar was found to be the least noisy place (69.7 dBA during $11 \mathrm{am} \mathrm{-} 3$ pm and 67.5 dBA during 3 p.m. - 7 p.m.). The noise level varies with traffic density and time of the day. The lowest level may be due to less density of population in Santosh. The noise level near bazars differed from shopping centers. Near road there was a high noise level because of high traffic movement. All values exceeded 60 dBA standard for residential areas set by MoEF (1997). 
One hundred students from three colleges and several schools of Tangail municipality area were interviewed. Almost over half (54\%) of the students were boys and 46\% were girls. Most of the students' age ranged between 15 and 20. Most of the students traveled to school or college by rickshaw (56\%), by tempo (12\%), by bus (6\%) and rest $26 \%$ traveled in other ways. Almost similar response was found from boys and girls when they were asked about the main causes of

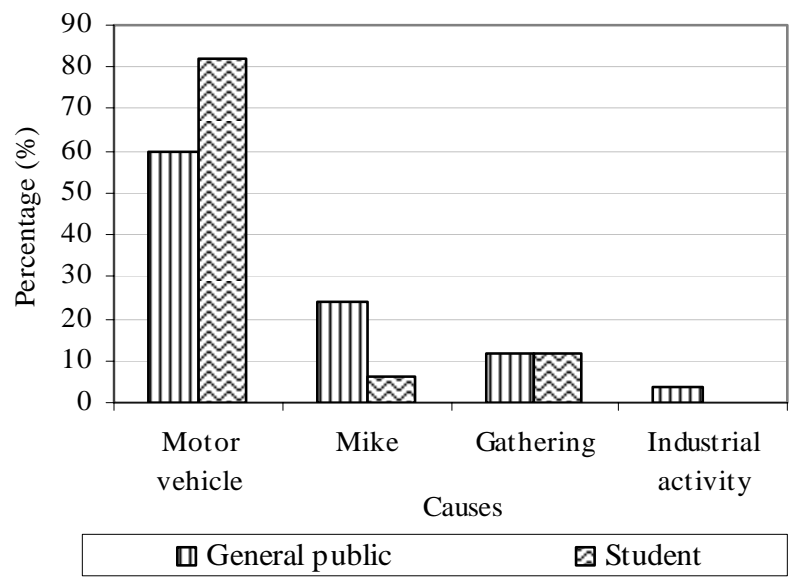

Fig. 4. Causes of noise pollution.

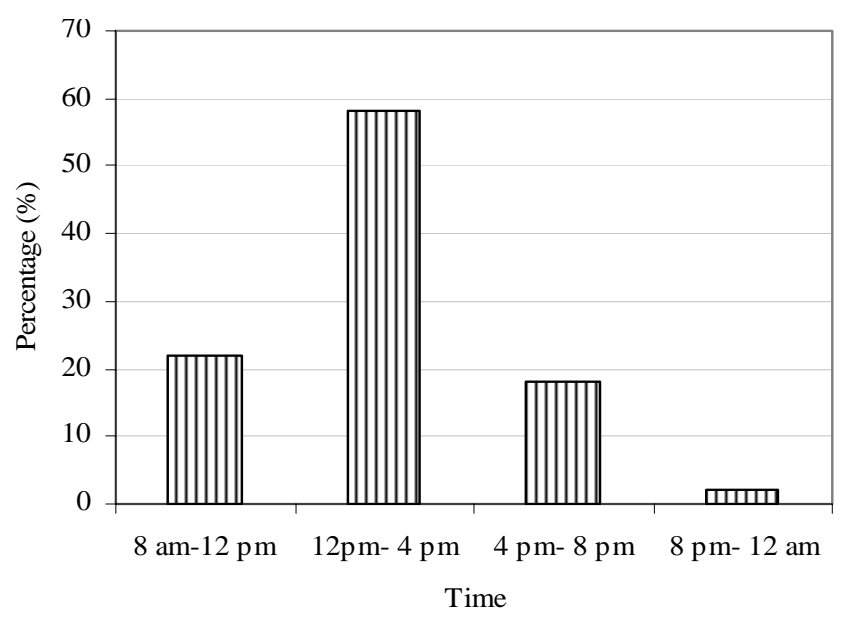

Fig. 5. Most disturbing time to students.

noise pollution. The most common identified causes of noise pollution were motor vehicle, loud speaker and human gathering. The causes the noise pollution according to respondents are given in Fig. 4. From Fig. 5 the most disturbing time was found to be 12 p.m. - 4 p.m. and least disturbing time from 8 p.m. - 12 a.m. 
From Fig. 6 it can be found that, among 100 students, majority of the students suffered from headache and comparatively lesser number of students were affected by hearing problem. Only a small percentage was affected by increased heart beat and drowsiness. Over half of the students recommended that public awareness can reduce noise pollution. The rest supported driving awareness and banning of hydraulic horns to reduce noise pollution. Only a small percentage of the students mentioned all the aforementioned measures (Fig. 7).

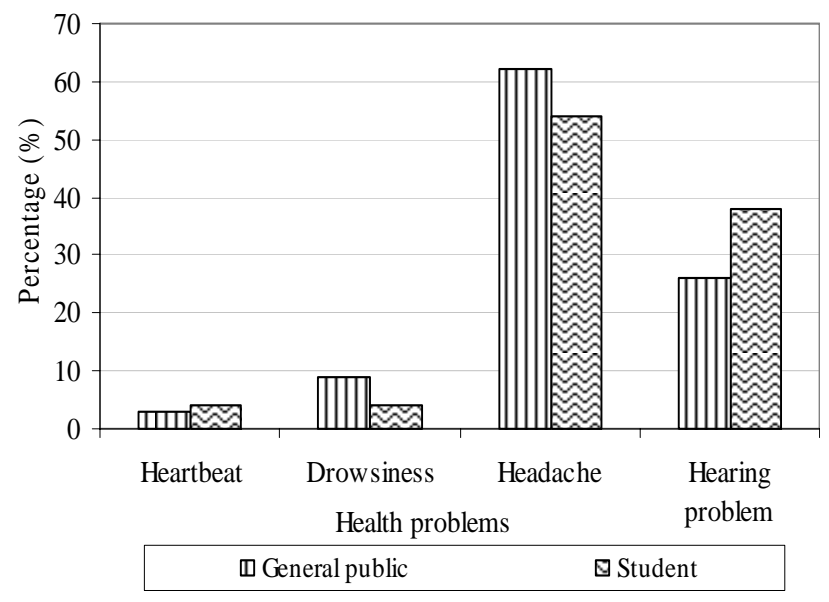

Fig. 6. Health problems due to noise pollution

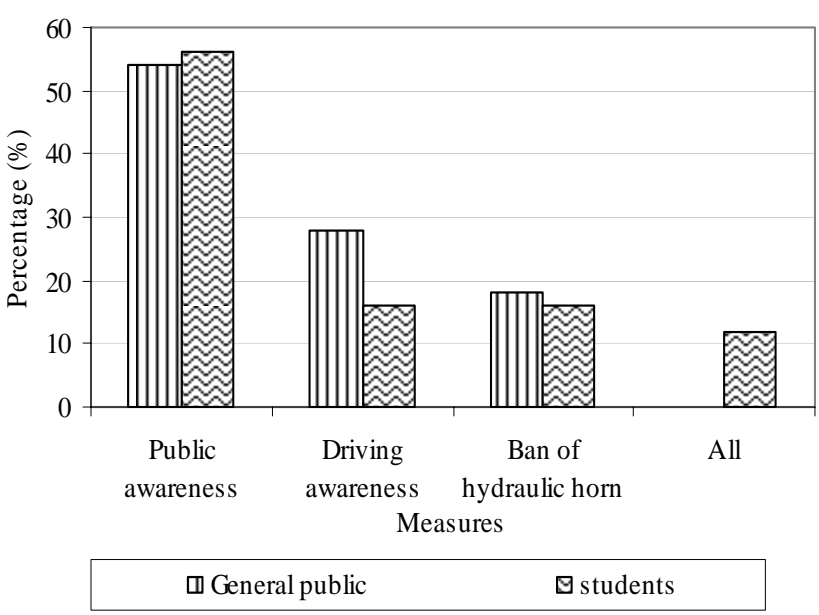

Fig. 7. Measures to combate noise pollution.

One hundred members of the general public were surveyed during the study. Among them $78 \%$ were male and $22 \%$ were female. Among them 33\% respondents were of the age range of 20 - 30, 35\% of the respondents from 30 - 40, 19\% from 40 - 50 and 15\% were from 50 - 60 years. Majority of the respondents mentioned motor vehicles as a cause of noise pollution (Fig. 4). Other 
than motor vehicles the respondents also mentioned about the high sound system, human gathering and industrial activity for noise pollution. The respondents suffered from many problems caused by noise pollution. The most common problems they were suffering are increased heart beat, drowsiness, headache and hearing problem. People were asked to give their suggestion to reduce noise pollution problems. To improve noise pollution almost half suggested for rising of public awareness, others suggested towards rising of driving awareness and a small percentage suggested for banning of hydraulic horn (Fig. 7).

It is found that noise level is closely related to the number of vehicles. The noise level on the main road near residential area, hospital area and educational area are above the acceptable limit. Special measures should be taken to combat noise pollution. Proper maintenance of vehicles should be implemented to control the level of noise pollution. The vulnerable institutions like school and hospitals should be located about $60 \mathrm{~m}$ away from the road side. The awareness of general public can play an important role to reduce noise pollution.

\section{References}

Aftab, T., F. Bashir and T. Shafiq. 2007. Road traffic noise pollution a hazard. Bangladesh J. Sci. Ind. Res. 42(4): 435-440.

Ahmad, A.J. and Khan, J.A. (2003) Traffic noise control in the city. NED Engineering Horizons XVI., 174

Alam, G.M.J. 2009. Environmental pollution of Bangladesh - it's effect and control. Proceedings of the International Conference on Mechanical Engineering held on 26 - 28 December 2009, Dhaka, Bangladesh.

Alam, M.J.B., A.F.M.A. Rauf and M.F. Ahmed. 2001. Traffic induced noise pollution in Dhaka city. Journal of Civil Engineering 29(1): 55-63.

Babish W., H. Ishing, P.C. Elwood, D.S. Sharp and D. Bainbton. 1993. Traffic noise and cardiovascular risk. Archives Environmental Health. 48: 406-413.

Das, S. 2001. A study on noise pollution in roads in Sylhet city. B.Sc. Engineering Thesis, Department of Civil and Environmental Engineering, Shahjalal University of Science and Technology, Sylhet, Bangladesh.

Ministry of Environment and Forest (MoEF). 1997. Environment Conservation Rules. Bangladesh Gazette. People’s Republic of Bangladesh. pp. 208.

Sultana, M.S., N. Jahan, M.S. Islam and S.M. Masum. 2011. Assessment of noise pollution in the Ashuganj fertilizer industrial area, Ashuganj. Bangladesh J. Sci. Ind. Res. 46(2): 183-190.

(Manuscript received on 30 May, 2013; revised on 15 December, 2013) 